\title{
Synthesis of Biotin-Modified Galactosylated Chitosan Nanoparticles and Their Characteristics in Vitro and in Vivo
}

\author{
Mingrong Cheng ${ }^{a} \quad$ Daxi Ma ${ }^{b}$ Kangkang Zhic Baochi Liud ${ }^{d}$ Weiping Zhue \\ aSchool of Life Sciences and Technology, Tongji University, Shanghai, 'Department of General Surgery, \\ Shanghai University of Medicine \& Health Sciences Affiliated Zhoupu Hospital, Shanghai, 'Department \\ of Vascular and Endovascular Surgery, Changzheng Hospital, Affiliated Hospital of the Second Military \\ Medical University, Shanghai, dDepartment of Surgery, Shanghai Public Health Clinical Center, Fudan \\ University, Shanghai, eDepartment of Hepatic Surgery, Fudan University Shanghai Cancer Center, \\ Shanghai Medical College, Fudan University, Shanghai, China
}

\section{Key Words}

Drug delivery system $\bullet$ Liver cancer $\bullet$ Curative effect $•$ Nanoparticles

\begin{abstract}
Background/Aims: Our previous study found that a nanoparticle drug delivery system that operates as a drug carrier and controlled release system not only improves the efficacy of the drugs but also reduces their side effects. However, this system could not efficiently target hepatoma cells. The aim of this study was to synthesize biotin-modified galactosylated chitosan nanoparticles (Bio-GC) and evaluate their characteristics in vitro and in vivo. Methods: Bio-GC nanomaterials were synthesized, and confirmed by fourier transform infrared spectroscopy (FTIR) and hydrogen ${ }^{-1}$ nuclear magnetic resonance $\left({ }^{1} \mathrm{H}-\mathrm{NMR}\right)$. The liver position and cancer target property of Bio-GC nanoparticles in vitro and in vivo was tested by confocal laser and small animal imaging system. The characteristics of Bio-GC/5-fluorouracil (5-FU) nanoparticles in vitro and in vivo were explored by cell proliferation, migration and cytotoxicity test, or by animal experiment. Results: Bio-GC nanoparticles were synthesized with biodegradable chitosan as the nanomaterial skeleton with biotin and galactose grafts. Bio-GC was confirmed by FT-IR and ${ }^{1} \mathrm{H}-\mathrm{NMR}$. Bio-GC/5-FU nanoparticles were synthesized according to the optimal mass ratio for Bio-GC/5-FU (1:4) and had a mean particle size of $81.1 \mathrm{~nm}$, zeta potential of $+39.2 \mathrm{mV}$, and drug loading capacity of $8.98 \%$. Bio-GC/5-FU nanoparticles had sustained release properties (rapid, steady, and slow release phases). Bio-GC nanoparticles targeted liver and liver cancer cell in vitro and in vivo, and this was confirmed by confocal laser scanning and small animal imaging system. Compared with GC/5-FU nanoparticles, Bio-GC/5-FU nanoparticles showed more specific cytotoxic activity in a dose- and time-dependent manner and a more obvious inhibitory effect on the migration of liver cancer cells. In addition, Bio$\mathrm{GC} / 5-\mathrm{FU}$ nanoparticles significantly prolonged the survival time of mice in orthotopic liver

M. Cheng, D. Ma, and K. Zhi contributed equally to this work.

\begin{tabular}{ll}
\hline Baochi Liu & Department of Surgery, Shanghai Public Health Clinical Center; Fudan University Shanghai 201508; \\
and Weiping Zhu & Department of Hepatic Surgery, Fudan University Shanghai Cancer Center, Shanghai Medical College, \\
& Fudan University, Shanghai 200032 (China), E-Mail liubaochi200227@aliyun.com; wpzhush@hotmail.com
\end{tabular}
\end{abstract}


cancer transplantation model compared with other 5-FU nanoparticles or 5-FU alone. Bio-GC (0.64\%) nanomaterial had no obvious cytotoxic effects on cells; thus, the concentration of Bio-GC/5-FU nanoparticles used was only $0.04 \%$ and showed no toxic effects on the cells. Conclusion: Bio-GC is a liver- and cancer-targeting nanomaterial. Bio-GC/5-FU nanoparticles as drug carriers have stronger inhibitory effects on the proliferation and migration of liver cancer cells compared with 5-FU in vitro and in vivo.

(C) 2018 The Author(s)

Published by S. Karger AG, Basel

\section{Introduction}

5-Fluorouracil (5-FU) is a cell cycle specific drug that can inhibit thymidylate synthase activity in tumor cells in vivo by blocking the biosynthesis of deoxythymidine from deoxyuridine and eventually inhibiting DNA synthesis [1,2]. Furthermore, it also can prevent uracil and orotic acid uptake into RNA to inhibit the effects of RNA, and thus interferes with the biosynthesis of RNA, DNA, and proteins [3, 4]. 5-FU has a broad anticancer spectrum and obvious curative effects, and either alone or in combination with other anticancer drugs, it plays an important role in the treatment of most common tumors of the digestive tract such as gastric cancer [5], colorectal carcinoma [6], and hepatoma [7]. To date, it cannot be replaced by other drugs, especially for the treatment of gastrointestinal tumors. However, 5-FU has many clinical shortcomings. Its half-life is only around 5-10 $\mathrm{min}$ in vivo; therefore, it takes a long time and high doses of 5-FU to maintain effective concentrations in the body. In addition, the absorption of 5-FU is irregular and elimination is nonlinear, and if the concentrations of 5-FU in vivo are too high, typical toxic side effects can occur that limit its clinical application $[6,8]$. In recent years, research into 5-FU preparations with high efficiency and low toxicity has become a popular area of investigation among many researchers.

Drug delivery systems are receiving widespread attention. Moreover, drug carriers with controlled release not only improve the efficacy of drugs but also reduce their side effects because of their structures and sustained release effects [9-13]. Because chitosan (CS) drug delivery systems provide sustained release, biodegradability, and surfaces that can be modified, they have become widely used in drug delivery system research [14]. CS has a large number of positive ions, and when they come into contact with negatively charged poly anionic compounds and biological macromolecules in aqueous solution, the structure can be modified by intramolecular or intermolecular crosslinking to form a gel and eventually nanoscale particles [15]. Because CS represents a non-targeted nanomaterial that has common nanoscale characteristics, we previously synthesized galactosylated chitosan (GC) nanoparticles by grafting CS with a galactose ligand, which is modified at the molecular level of CS [16]. Asialoglycoprotein receptor (ASGPR) is found on sinusoidal surfaces of mammalian liver cells and is a glycoprotein that specifically recognizes terminal galactose residues or acetylamino galactose. Each hepatocyte contains about 200, 000 binding sites for ASGPR [17]. The specific binding of galactose ligand with ASGPR on hepatocyte membranes has been shown to induce liver-targeted drug transfer.

In our previous study, we synthetized GC/5-FU nanoparticles by combining the GC material with 5-FU, and tested its effects in an orthotropic liver cancer mouse model. We found that the GC/5-FU nanoparticles specifically target the liver and liver cancer cells, and that the deficiency of GC/5-FU nanoparticles increased the concentration of 5-FU in normal liver tissues [18]. Therefore, we synthesized nanomaterials targeting liver cancer based on preliminary research that aimed to improve liver cancer targeting and reduce the drug concentrations in liver tissue. Cancer cell growth is due to the overexpression of some vitamin receptors as they try to adapt to the need for a large number of vitamins. Biotin (also called vitamin $\mathrm{H}$ ) is a small molecular compound with a molecular mass of $244 \mathrm{Da}$, and the expression of its receptor is 39.6 times higher in hepatocellular carcinoma cells than in normal liver cells [19]. HepG2 cells show strong adsorption of D-biotin-modified nanoparticles, and as the concentration of biotin increases, the adsorption also increases significantly [20]. We used galactose (targeting the liver ) and biotin (targeting the cancer), in combination with CS to synthesize galactosylated CS modified by biotin (Bio-GC, which is liver- and cancer cell-specific), based on our previous work. We explored the characteristics of Bio-GC/5-FU nanoparticles in vitro and in vivo and their inhibitory effects on liver cancer cells. 


\section{Cellular Physiology Cell Physiol Biochem 2018;50:569-584

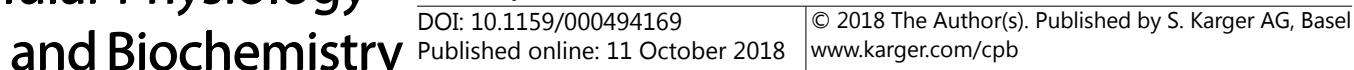 \\ Cheng et al.: Inhibitory Effects of Bio-GC Nanoparticles Targeting Liver Cancer}

\section{Materials and Methods}

\section{Experimental materials}

The experimental materials included CS (>85\% degree of deacetylation, Sigma-Aldrich, St. Louis, MO, USA); $N$-hydroxysuccinimide (NHS), 1-ethyl-3-(3-dimethylaminopropyl) carbodiimide hydrochloride, Aldrich), and RNase (all Sigma-Aldrich); biotin (Beijing Jiakangyuan Pharmaceutical Co., Ltd., Beijing, China); $\mathrm{HCl}$ (HCl, AR grade, Shanghai Reagent Company, Shanghai, China); calf serum (Hangzhou Sijiqing Pharmaceutical Co., Ltd., Hangzhou, China); Hoechst 33258 nuclear dye (Sigma-Aldrich); RPMI 1640 powder (GIBCO, Invitrogen Inc., Carlsbad, CA, USA); Cell Counting Kit-8 (CCK-8, Dojindo Molecular Technologies Inc., Shanghai, China), and tetramethylethylenediamine (Sinopharm Chemical Reagent Co., Ltd., Shanghai, China). GC was synthesized and stored in our laboratory.

\section{Experimental animals and cell lines}

Human hepatocellular carcinoma cells (SMMC-7721) and normal liver cells (LO2) were obtained from the Committee on Type Culture Collection of the Chinese Academy of Sciences (Shanghai, China). A human colon cancer cell line (SW480) was purchased from the American Type Culture Collection (Manassas, VA, USA). Hepatocarcinoma 22 (H22) cell line was purchased from the China Center for Type Culture Collection (Wuhan, China). Female BALB/c mice, aged 7 weeks and weighing about $25 \mathrm{~g}$, were obtained from the Science Department of Experimental Animals of Fudan University in China.

\section{Synthesis of Bio-GC}

Lactose (1.55 g) was added into CS (1.01 g) solution at room temperature, and the solution reacted until clarified. $\mathrm{NaBH}_{4}$ was slowly added into the solution and reacted at room temperature for $72 \mathrm{~h}$. After the reaction, GC was collected following dialysis and freeze dried. The biotin was first dissolved in $N, N$ dimethylformamide, and NHS and dicyclohexylcarbodiimide were added into the solution after the biotin was completely dissolved. Crude bio-NHS was synthesized in a 16-h reaction and then filtered to remove byproducts such as dicyclohexylurea, and further purified to obtain purer biotin ester. GC was dissolved, and biotin ester (Bio-NHS) solution was dripped into the GC solution (20-30:1 molar ratio of biotin to chitosan). After $24 \mathrm{~h}$, the Bio-GC was collected following dialysis and freeze-dried.

\section{Fourier transform infrared spectroscopy (FT-IR)}

Powdered samples of galactosyl glucose, biotin, CS, GC, and Bio-GC were pressed into a potassium bromide (KBr) pellet and infrared spectra records of each sample were recorded using a Nexus Fourier Transform Infrared Spectrometer (Nicolet ${ }^{\mathrm{TM}}$ Natus Medical Incorporated, San Carlos, CA, USA) in the range $400-4000 \mathrm{~cm}^{-1}$.

\section{Hydrogen-1 nuclear magnetic resonance spectroscopy $\left({ }^{1} H-N M R\right)$}

To further verify the chemical structure of the synthesized end-product, CS was tested by ${ }^{1} \mathrm{H}-\mathrm{NMR}$ (600 MHz, Agilent Technologies, Santa Clara, CA, USA). The sample was dissolved in a mixed solution of hydrochloric acid and deuterated heavy water, with tetramethylsilane as an internal standard.

\section{Preparation of Bio-GC/5-FU nanoparticles}

Bio-GC was put into the centrifuge tube, and Bio-GC solution was obtained by adding AcOH, deionized water, and $50 \mathrm{mmol} / \mathrm{L} \mathrm{NaAc}$ and warming the mixture in a $45-50{ }^{\circ} \mathrm{C}$ water bath for $5-10 \mathrm{~min}$. 5 -FU was placed in the $45-50^{\circ} \mathrm{C}$ water bath and heated for 5-10 min, and quickly added into the Bio-GC solution (10:1 mass ratio of 5-FU to Bio-GC). The solution was immediately vortexed for $30 \mathrm{~s} \mathrm{(2000} \mathrm{rpm)} \mathrm{and} \mathrm{maintained}$ at room temperature for over $30 \mathrm{~min}$. After $4000 \mathrm{rpm}$ centrifugation, deionized water was used to wash away the residue. The solution was centrifuged and washed again after dispersion of the residue to remove $\mathrm{NaOH}$ and 5-FU, re-dispersed in deionized water, freeze dried, and stored.

\section{Determination of particle size and zeta potential}

The drug-loaded nanoparticle suspension was added to a cuvette, which was placed into the sample holder to detect the particle size and distribution of nanoparticles. The suspension of nanoparticles was added into the zeta potential pipeline via a 5-mL syringe. The zeta potential and average particle size of the nanoparticles were detected by Zetasizer Nano-Z (Malvern Instruments, Malvern, UK), and particle shapes were determined using a TECNA10 transmission electron microscope (Philips Company, Philips, the Netherlands). To determine the encapsulation efficiency, an ultraviolet (UV) spectrophotometer (Beckman DU-650, Beckman Coulter Inc., Brea, CA, USA) was used to detect the concentration of DNA in the collected supernatant and the DNA was calculated relative to the volume. 


\section{Cellular Physiology Cell Physiol Biochem 2018;50:569-584

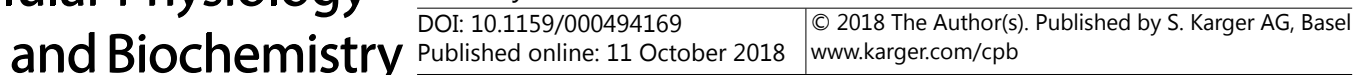 \\ Cheng et al.: Inhibitory Effects of Bio-GC Nanoparticles Targeting Liver Cancer}

\section{Preparation of 5-FU standard curve}

The chromatographic conditions were as follows: chromatographic column, $\mathrm{C}_{18}(250 \mathrm{~mm} \times 4.6 \mathrm{~mm}, 5$ $\mu \mathrm{m}$ ); column temperature, room temperature; flow rate, $0.8 \mathrm{~mL} / \mathrm{min}$; mobile phase, methanol-water (ratio 15:85); wavelength, $265 \mathrm{~nm}$; and injection volume, $20 \mathrm{~L}$.

5-FU was weighed accurately and prepared to a final concentration of $10 \mathrm{mg} / \mathrm{L}$, then scanned by UV spectrophotometry (Beckman DU-650) in the range 200-400 $\mathrm{nm}$. The maximum absorption wavelength of 5 -FU was $265 \mathrm{~nm}$. 5-FU was added into $0.5 \mathrm{~mL}$ simulated body fluid (SBF) and dissolved to give concentrations of $0.1,0.2,0.5,1.0,5.0,10$, and $20 \mathrm{mg} / \mathrm{L}$ in $10 \mathrm{~mL}$ standard serum, and absorption was measured at $265 \mathrm{~nm}$. Linear regression was performed by placing absorbance on the Y axis and the concentration of 5-FU (mg/L) on the $\mathrm{X}$ axis.

\section{Release of Bio-GC/5-FU nanoparticles in vitro}

A certain amount of Bio-GC/5-FU nanoparticles and 5-FU were weighed and placed into a dialysis bag, and $30 \mathrm{~mL} \mathrm{SBF}$ was added to form a mixed suspension (pH 7.4), which was oscillated (frequency $60 \mathrm{rpm}$ ) by dynamic dialysis at a constant temperature $\left(37^{\circ} \mathrm{C}\right)$. The dialysis fluid was removed at $0 \mathrm{~min}, 20 \mathrm{~min}, 40$ min, $60 \mathrm{~min}$, and each day from days 1 to 10 . Fresh SBF was added to maintain the original volume of $30 \mathrm{~mL}$. Absorbance values were measured at a wavelength of $265 \mathrm{~nm}$. The release of 5-FU nanoparticles at different times were calculated using a standard absorption curve. The concentration was calculated according to the standard curve equation, and the means of 3 experiments were recorded. Cumulative drug release $(\%)=$ (release of 5-FU from samples)/(total amount of 5-FU) $\times 100 \%$.

Nanoparticles were dissolved in 1\% HCL and diluted with SBF and compared with SBF as the control to determine the absorbance at $265 \mathrm{~nm}$. According to the SBF standard curve of 5-FU, the encapsulation efficiency and drug loading capacity of the Bio-GC nanoparticles were calculated as follows:

encapsulation efficiency $(\%)=([$ amount of DNA within a nanoparticle $]-$ [amount of DNA in the supernatant])/(total amount of DNA added) $\times 100 \%$

drug loading $(\%)=($ amount of DNA within nanoparticles $) /($ nanoparticle mass $) \times 100 \%$

\section{Bio-GC nanoparticles targeting liver cancer in vitro}

SMMC-7721 and LO2 cells were seeded in 6-well plates and incubated for $24 \mathrm{~h}$. Fresh medium containing different Bio-GC, GC, Bio-CS, and CS nanoparticles marked with fluorescein isothiocyanate (FITC) was added, and the cells were further incubated for $4 \mathrm{~h}$. Cells were then stained with the fluorescent dye Hoechst 33258 and washed with $0.01 \mathrm{~mL}$ phosphate-buffered saline (PBS) 3 times. Cells were then fixed in $4 \%$ paraformaldehyde at room temperature for $20 \mathrm{~min}$. Cover slips were removed with tweezers and placed on glass slides mounted with glycerol buffer solution. The fluorescent signals in the samples were observed by a confocal laser scanning microscope (Olympus FV-1000, Tokyo, Japan). The excitation wavelength of the fluorescent nanoparticles was $488 \mathrm{~nm}$ and that of Hoechst 33258 was $405 \mathrm{~nm}$. Images were photographed and stacked via the imaging software NIS Elements. In vitro experiments using LO2 and SMMC-7721 as model cells were observed by confocal microscopy to assess the endocytosis processes of Bio-GC nanoparticles, and the fluorescence intensity was detected.

\section{Animal model}

H22 cells were used to establish an animal mouse liver subcutaneous model. The tumor tissue was dissected after the mice were sacrificed and tumors showing vigorous growth were selected. Tumor cell suspension was generated at a density of $6 \times 10^{7} / \mathrm{mL}$. A median incision was performed after intraperitoneal anesthesia with $20 \%$ urethane, and $50 \mu \mathrm{L}$ of $\mathrm{H} 22$ suspension was injected into the left lobe of the liver capsule via a 1-mL syringe. After $2 \mathrm{~min}$, the abdomen was closed layer by layer to ensure no leaking, and the orthotopic transplantation liver cancer model was successfully established.

\section{Dynamic imaging of Bio-GC nanoparticles in vivo}

To ensure the consistency of the fluorescence signal intensities of the modified nanoparticles, some amino acids from the CS skeleton and isothiocyanate Rhodamine B (RBITC) were first reacted to produce RBITC-CS labeled with isothiocyanate Rhodamine B, then RBITC-Bio-CS, RBITC-GC and RBITC-Bio-GC were synthesized. The orthotopic transplantation liver cancer model was established after day 5, and the RBITCCS, RBITC-Bio-CS, RBITC-GC, and RBITC-Bio-GC nanoparticles were injected into the tail veins at doses of $0.4 \mathrm{mg} / 20 \mathrm{~g}$ of mouse weight. Dynamic observation of CS, Bio-CS, GC, and Bio-GC among the mice was performed via a small animal imaging system in vivo (Maestro ${ }^{\mathrm{TM}}, \mathrm{CRi}$, Woburn, MA, USA) at $2,4,8,12$, and $24 \mathrm{~h}$, and 3 mice from each group were euthanized at each time point. The fluorescence intensities in liver, kidney, spleen, and brain tissues were tested, which reflected the amount of nanoparticles at each site. The remaining mice were sacrificed at $24 \mathrm{~h}$, and the fluorescence photon numbers in the liver and liver cancer 


\section{Cellular Physiology Cell Physiol Biochem 2018;50:569-584 and Biochemistry Published online: 11 October 2018 \begin{tabular}{l|l} 
DOI: 10.1159/000494169 2018 The Author(s). Published by S. Karger AG, Basel \\
www.karger.com/cpb
\end{tabular} \\ Cheng et al.: Inhibitory Effects of Bio-GC Nanoparticles Targeting Liver Cancer}

regions were detected by the CRi Maestro ${ }^{\mathrm{TM}}$ imaging detection system and the hepatic cancer (C) and liver (L) fluorescence ratio was calculated. The $\mathrm{C} / \mathrm{L}$ ratio reflected the ability of the nanoparticles to target liver cancer specifically.

\section{Cell proliferation and cytotoxicity test}

Cells proliferation and cytotoxicity were tested by cell counting kit-8 (CCK-8) assay. SW480 cells and SMMC-7721 cells were cultured in RPMI-1640 supplemented with 10\% FBS in a humidified incubator containing $5 \% \mathrm{CO}_{2}$ at $37^{\circ} \mathrm{C}$. $\mathrm{H} 22$ cells were collected, counted, and centrifuged at $1000 \mathrm{rpm}$ for $5 \mathrm{~min}$ and the cell density was adjusted with the culture medium. Cells were seeded into 96-well plates at a density of 1, 000 cells $/ 100 \mu \mathrm{L}$ per well. The drugs (5-FU, Bio-GC, CS/5-FU, GC/5-FU, and Bio-GC/5-FU) were prepared in RPMI-1640 complete medium at concentrations of $10,3,1,0.3,0.1,0.03$, and $0.01 \mathrm{mg} / \mathrm{L}$. The medium in 96-well plates (Dojindo, Kumamoto, Japan) was gently removed and the configured complete culture medium was added at different concentrations according to the experimental design. Subsequently, $10 \mu \mathrm{L}$ CCK-8 (Sigma-Aldrich, St. Louis, MO, USA) solution was added to each well, and the plates were incubated at $37^{\circ} \mathrm{C}$ for $2 \mathrm{~h}$. The optical density (OD) was measured at $450 \mathrm{~nm}$ using Bio-Rad automatic micro-plate reader (Bio-Rad, Hercules, CA, USA) 3 times for each group at 3 different times points, namely, 24, 48, and $72 \mathrm{~h}$. Meanwhile, the cells treated with 5-FU at a final concentration of $0.3 \mathrm{mg} / \mathrm{L}$ were measured 3 times on days $1,2,3,4,5$, and 6 , and the tumor inhibition rate was calculated by the following formula: (tumor inhibition rate $)=([\mathrm{A} 450$ in the control well $]-[\mathrm{A} 450$ in the test well $]) /(\mathrm{A} 450$ in the control well $) \times 100 \%$.

Solutions with different concentrations of Bio-GC nanoparticles $(0.01 \%, 0.04 \%, 0.16 \%, 0.64 \%)$ were dissolved in RPMI-1640. Bio-GC solution $(200 \mu \mathrm{L})$ at different concentrations were added into each experimental well. The negative control groups were SMMC-7721, SW480, and LO2 cells without added nanoparticles. The blank control groups contained RPMI-1640 medium. After 3 days of culture, $10 \mu \mathrm{L}$ CCK-8 solution was added to each well, and the plates were incubated at $37^{\circ} \mathrm{C}$ for $2 \mathrm{~h}$. The OD was measured at 450 $\mathrm{nm}$ using the Bio-Rad automatic microplate reader 3 times per group, and the relative cell proliferation ratio was calculated by the following formula: (relative cell proliferation ratio $)=([O D$ at different concentrations group - [OD of blank control group])/([OD of negative control group] - [OD of blank control group]) $\times$ $100 \%$. The relative cell proliferation ratio was used to evaluate the cytotoxic effects.

\section{Cell migration experiment}

The migration capacity was analyzed using transwell assays. Fibronectin gel ( $50 \mu \mathrm{L}$ of $5 \mu \mathrm{g} / \mathrm{mL}$ ) (ProSpec-Tany TechnoGene Ltd., Ness-Ziona, Israel) was dropped into transwell cells (Corning Inc., Corning, NY, USA) and dried in a biosafety cabinet overnight. SMMC-7721 cells were cultured in RPMI-1640 (Invitrogen) containing 10\% FBS (GIBCO) in a humidified incubator containing $5 \% \mathrm{CO}_{2}$ at $37{ }^{\circ} \mathrm{C}$. The cells were collected and counted, then further centrifuged at $1000 \mathrm{rpm}$ for $5 \mathrm{~min}$, and cell density was adjusted with RPMI-1640. The cells were seeded in the upper chamber without serum at 2000 cells $/ 100 \mu \mathrm{L}$ per well, and $500 \mu \mathrm{L}$ RPMI-1640 containing 10\% FBS was added to the lower chamber. The 5 drugs (5-FU, Bio-GC, $\mathrm{CS} / 5-\mathrm{FU}, \mathrm{GC} / 5-\mathrm{FU}$, and Bio-GC/5-FU) were added into the upper chamber, in which the concentration of 5 -FU was $3 \mathrm{~g} / \mathrm{mL}$. After culture for $48 \mathrm{~h}, 50 \mu \mathrm{L} 0.5 \%$ crystal violet solution was added to the upper chamber and photographed. The cells in the lower chamber were digested using trypsin and a $20-\mu \mathrm{L}$ cell suspension was produced. The counting plate pool was filled with a small amount of suspension, and the number of cells across the membrane was counted under the microscope (x200) across 5 fields (upper, middle, lower, left, and right). The migration ability was assessed by the number of cells that crossed the membrane. Counts were repeated 3 times.

\section{Effect of Bio-GC/5-FU nanoparticles on orthotopic transplantation liver cancer model}

On day 5 after the liver transplantation model was established in mice, the liver cancer tissue was about 4-6 mm. The animals were divided into 6 groups: control, Bio-GC, 5-FU, CS/5-FU, GC/5-FU, and BioGC/5-FU. In the control group, $200 \mu \mathrm{L}$ of normal saline was intravenously injected, and in the Bio-GC group, $200 \mu \mathrm{L}$ empty nanoparticles were injected into the tail vein. In the 5-FU, CS/5-FU, GC/5-FU, and Bio-GC/5FU groups, $200 \mu \mathrm{L}$ of the corresponding drugs were administered (including $0.371 \mathrm{mg} 5$-FU). Six days after the model was established, the drugs were administered via the tail veins for 5 days. Survival analysis of the remaining 9 mice in each experimental group was performed.

\section{Statistical analysis}

All data are expressed as the mean \pm standard deviation. Data between groups were compared using one-way analysis of variance, and data between the groups were compared using the least significant difference method. The survival times of the mice were analyzed by the Kaplan-Meier method. A P-value less than 0.05 was considered statistically significant. 


\section{Cellular Physiology Cell Physiol Biochem 2018;50:569-584 and Biochemistry Published $\begin{aligned} & \text { DOI: 10.1159/000494169 } \\ & \text { (c) } 2018 \text { The Author(s). Published by S. Karger AG, Basel } \\ & \text { www.karger.com/cpb }\end{aligned}$

\section{Results}

FT-IR and ${ }^{1} H-N M R$ of
Bio-GC
As shown in Fig. $1 \mathrm{~A}$ (c), the infrared spectrum of CS shows 3 characteristic absorption peaks associated with the amide bond: amide band I at $1,653 \mathrm{~cm}^{-1}$, amide band II at 1, 600 $\mathrm{cm}^{-1}$, and amide band III at $1,322 \mathrm{~cm}^{-1}$, by which the weak absorption peaks of amide I and the strong absorption peaks of amide II represent the high degree of CS deacetylation. The $\mathrm{O}-\mathrm{H}$ and N-H stretching vibration peak appears at $3420 \mathrm{~cm}^{-1}$, and the $\mathrm{C}-\mathrm{H}$ stretching vibration peak was represented by a wave at $2882 \mathrm{~cm}^{-}$ 1. Compared with the infrared spectra of CS, that of GC in Fig. 1A (d) showed that because of reductive amination of a newly formed - $\mathrm{CH} 2$ $\mathrm{NH}-$, the antisymmetric stretching vibrations at $2921 \mathrm{~cm}^{-1}$ and $2881 \mathrm{~cm}^{-1}$ were strengthened, and the absorption peaks of CS amide I and amide II occurred in red shift (amide bonds I, II, and III decreased from 1653 $\mathrm{cm}^{-1}, 1600 \mathrm{~cm}^{-1}$, and $1322 \mathrm{~cm}^{-1}$ to $1647 \mathrm{~cm}^{-1}, 1597 \mathrm{~cm}^{-1}$, and $1320 \mathrm{~cm}^{-1}$, respectively), and amide I peak changed relatively sharply and the peak intensity of amide II weakened. These spectral changes suggested that the chemical reactions took place in the new amino group, and the galactose molecule was successfully grafted onto the surface of the CS molecules through -CH2-NHand an amide bond. In a comparison of Fig. 1A (e) and (d), IR of the Bio-GC material showed greater intensity and a sharp absorption peak at $1681 \mathrm{~cm}^{-1}$ through reductive amination, and we considered that biotin and CS were bonded together by an amide bond through a reaction between the amino group of CS and the carboxylamide of biotin leading to the absorption peaks of amide bond I. In addition, amides II and III were changed, and the absorption peaks of the amide bonds of II and III decreased from $1597 \mathrm{~cm}^{-1}$ and $1320 \mathrm{~cm}^{-1}$ to $1300 \mathrm{~cm}^{-1}$ and $1557 \mathrm{~cm}^{-1}$, respectively. The changes in the molecular structures suggested that biotin was successfully grafted onto the GC.

Fig. 1B (a) shows that the absorption peak at 2.0 ppm represented the protons in the $\mathrm{N}-\mathrm{CH}_{3}$ of CS, $3.16 \mathrm{ppm}$ represented the proton absorption peak of the amino group, and 3.88 ppm represented the proton absorption peak of hydroxyl groups. In comparing the GC (Fig. 1B (c)) with CS (Fig. 1B (b)) and lactose (Fig. 1B (a)), the proton peak of methyl of the raw acetamide groups in the synthesis of CS appeared at $1.99 \mathrm{ppm}$, and the range 4.0-4.5 ppm 
showed the characteristic peaks of galactose (with galactosyl structure), while the new absorption peak at 4.189 was attributed to the $\mathrm{H}$ proton signal peaks of galactose residues in the side chain. Thus, the lactose was successfully grafted onto the CS amino groups. A comparison of Bio-GC (Fig. 1B (d)) and GC (Fig. 1B (b)) showed the characteristic proton peaks of biotin in the range 1.3-1.7 ppm and 2.0-3.0 ppm, respectively, and the proton peak in the range of 4.0-4.5 ppm was strengthened. Ultimately, biotin was grafted onto the amide bond of the GC material, and the synthesis of Bio-GC material was successful.

\section{Synthesis and} characterization of BioGC/5-FU nanoparticles

As shown in Fig. 2A, the increase in the mass ratio of carrier and drug (Bio-GC/5FU), led to a gradual increase in drug loading while the encapsulation efficiency initially increased and then decreased. When the mass ratio of carrier and drug was in the range $1: 1$ to $1: 4$, the encapsulation efficiency

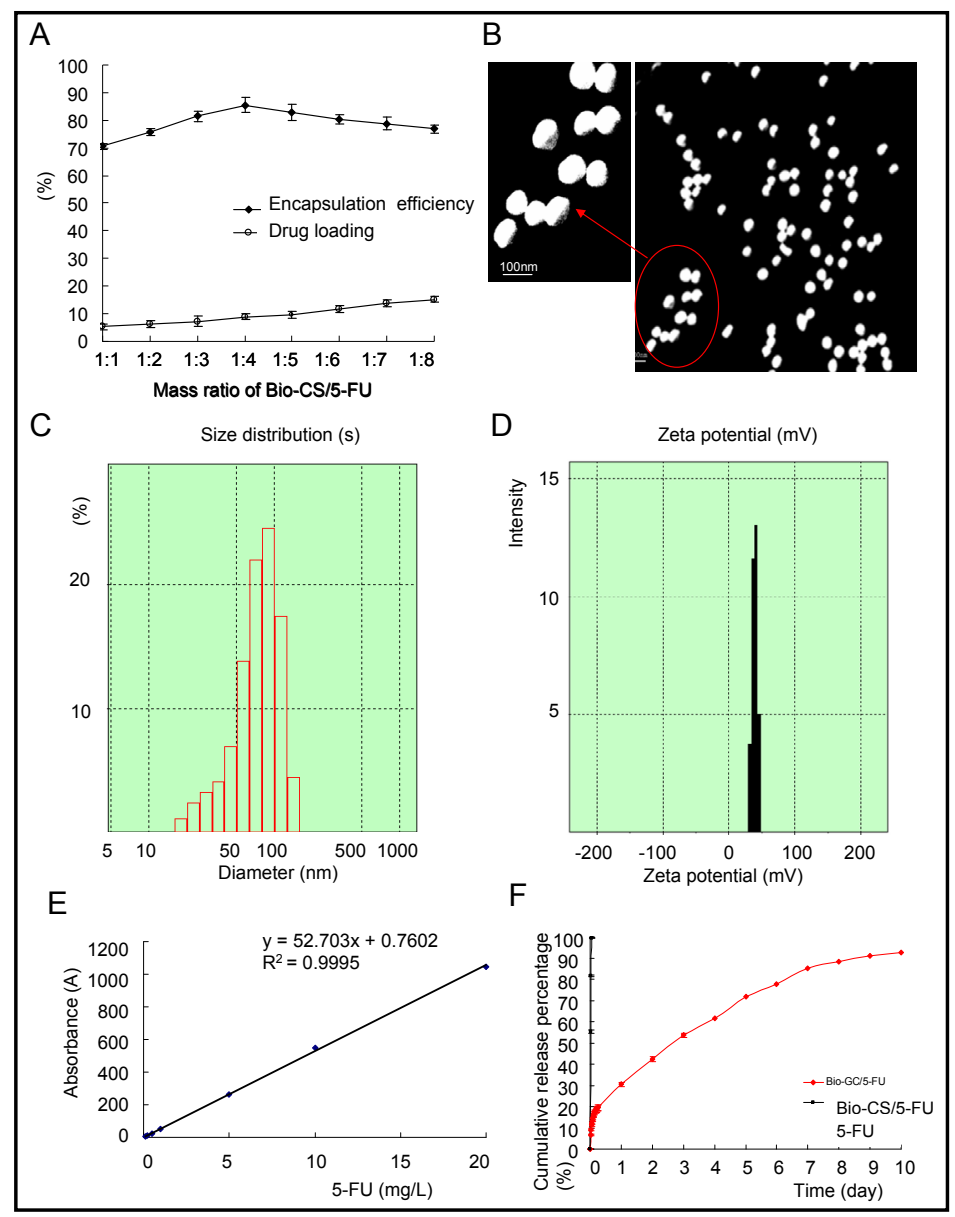

Fig. 2. Characteristics of Bio-GC/5-FU nanoparticles. A: 5-FU loading optimization of Bio-GC nanoparticles. B: Transmission electron micrograph of Bio-GC/5-FU nanoparticles. C: Particle size graph of BioGC. D: Zeta potential graph of Bio-GC. E: Standard curve of Bio-GC. F: Release curve of Bio-GC/5-FU nanoparticles in SBF $\left(37^{\circ} \mathrm{C}, \mathrm{pH} 7.4\right)$ in vitro. increased gradually as the mass ratio increased, while the encapsulation rate decreased significantly from 1:4 to 1:8. Therefore, the best mass ratio for Bio-GC/5-FU is 1:4 and, consequently, in our study, BioGC/5-FU nanoparticles were synthesized according to a mass ratio of Bio-GC/5-FU of 1:4. As shown in Fig. 2B, transmission electron microscopy of Bio-GC/5-FU nanoparticles suggested that Bio-GC/5-FU nanoparticles were spherical in shape with smooth surfaces and uniform size. The particle size analyzer showed that the Bio-GC/5-FU nanoparticles were $81.1 \mathrm{~nm}$ (Fig. 2C), and the polydispersity index was 0.16 , which indicated that the nanoparticles had good dispersion properties. The zeta potential was $+39.2 \mathrm{mV}$ and the drug loading capacity was $8.98 \%$ (Fig. 2D). As shown in Fig. 2E, the concentration of 5-FU, in the range 0.1-20 $\mathrm{mg} / \mathrm{L}$, had a good linear relationship with the absorbance, for which the regression equation was $y=52.703 x+0.7602(r=0.9995)$. The cumulative release rate of 5-FU in SBF over $1 \mathrm{~h}$ was $99.4 \%$ (Fig. 2F), and showed nearly linear rapid release. The release of Bio-GC/5-FU had 3 obvious stages: rapid release stage lasted $0-1$ days and due to the rapid diffusion of nanoparticles surface or nanoparticle shallow layer into the SBF, the cumulative release rate was $30.4 \%$. The steady release stage was 1-6 days, and the cumulative release rate was $77.8 \%$, that is, an increase of $47.4 \%$. The slow release phase was 7-10 days, during which the release curve was horizontal and release occurred at a slower pace. On day 10 the cumulative release rate was $92.5 \%$ and had increased by only $7.4 \%$. 


\section{Cellular Physiology and Biochemistry Published on \begin{tabular}{l|l} 
DOI: 10.1159/000494169 & (c) 2018 The Author(s). Published by S. Karger AG, Basel \\
www.karger.com/cpb
\end{tabular}

Fig. 3. Liver cancer targeting of Bio-GC nanoparticles in vitro and in vivo. A: Liver cancer targeting of BioGC nanoparticles in vitro. $\mathrm{CS}$, Bio-CS, GC, and Bio-GC nanoparticles labeled with FITC were incubated with SMMC-7721 and LO2 cells for $4 \mathrm{~h}(\mathrm{n}=3)$. Fluorescence images were taken by laser confocal microscope after the nuclei were stained with fluorescent Hoechst 33258 dye. B: Dynamic image of Bio-GC nanoparticles in orthotopic transplantation liver cancer model. After orthotopic liver transplantation model was established at day 5, RBITC-CS, RBITC-Bio-CS, RBITC-GC, and RBITCBio-GC nanoparticles labeled by isothiocyanate Luo Damming $B$ were injected into the tail veins of mice, and the dynamic

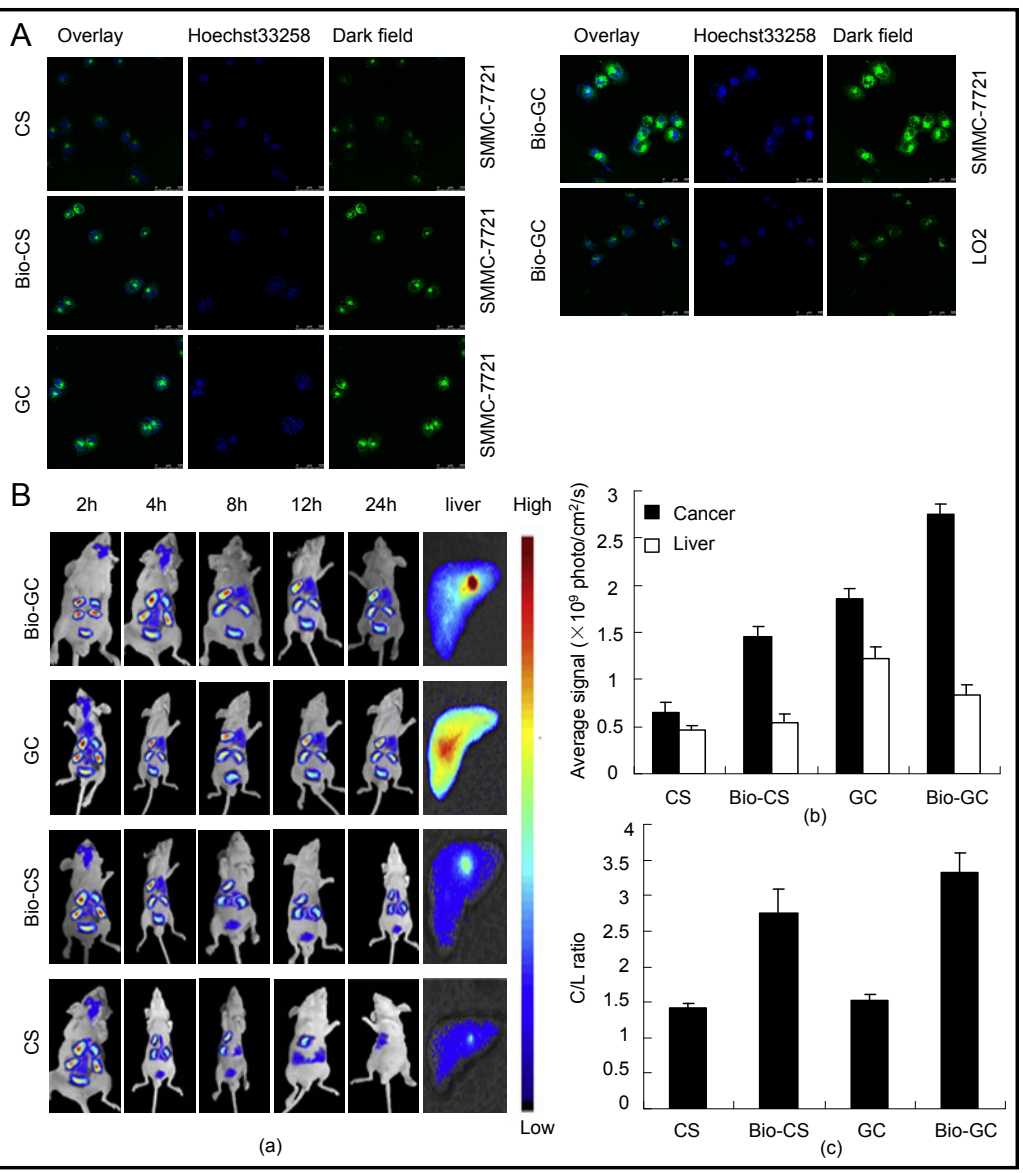
distributions of the materials were observed by a small animal imaging system in vivo at 2, 4, 8, 12, and $24 \mathrm{~h}(\mathrm{n}=3)$. (a): Images of orthotopic transplantation liver cancer models in vivo by a small animal imaging system from each group at different time points in liver cancer and liver tissue at $24 \mathrm{~h}$. (b): Histogram of the fluorescence photon numbers. (c): Histogram of C/L ratio in the liver at $24 \mathrm{~h}$.

\section{Liver cancer target of Bio-GC}

SMMC-7721 cells showed the strongest green fluorescence in the presence of Bio-GC nanoparticles, and the fluorescence was significantly higher than that with single cancer target materials (Bio-CS and GC). Green fluorescence was weakest in nanomaterials that did not target cancer (CS), which showed that Bio-GC mediated endocytosis was stronger than single or non-cancer-targeting nanomaterials. At the same time, we found that after treatment, only a small amount of green fluorescence was apparent in LO2 cells in the presence of Bio-GC; thus, Bio-GC nanoparticles had a strong ability to target liver cancer cells.

\section{Dynamic imaging of Bio-GC in orthotopic liver cancer transplantation in mice}

To understand the dynamic distribution of the nanoparticles in an orthotopic transplantation liver cancer model, nanoparticles were labeled with red fluorescent isothiocyanate Rhodamine B. As shown in Fig. 3B (a) and (b), the fluorescence intensity in CS was weaker in liver or liver cancer tissue at $24 \mathrm{~h}$, and significantly enhanced in liver cancer tissue at $24 \mathrm{~h}$ in the presence of Bio-CS with liver cancer targeting nanomaterials $(\mathrm{P}<0.01)$, but there was no significant difference in fluorescence intensity in liver tissues between BioCS and CS (P > 0.05) treatments. The fluorescence intensity of liver cancer in GC with nonspecific hepatic cancer targeting nanomaterials was significantly higher than that of CS and Bio-CS at $24 \mathrm{~h}(\mathrm{P}<0.01)$, and in liver tissue it significantly increased in the presence of GC compared with CS or Bio-CS $(\mathrm{P}<0.01)$. The strongest fluorescence intensity in liver cancer was observed at $24 \mathrm{~h}$ in the presence of Bio-GC with liver and cancer targeting properties 
Fig. 4. Inhibitory effect of Bio-GC/5FU nanoparticles on liver cancer. A: Inhibitory rate of Bio-GC/5-FU n a no particles on SW480 and SMMC-7721 cells. The data are expressed as the means \pm SD $(\mathrm{n}=$ 3). (a): Inhibitory rate curve of SW480 and SMMC7721 at different concentrations of 5-FU at 24 h. (b): Inhibitory rate curve of SW480 and SMMC7721 at different concentrations of 5-FU at 48 h. (c): Inhibitory rate curve of SW480 and SMMC7721 at different concentrations of 5-FU at $72 \mathrm{~h}$. (d): Inhibitory rate curve of SW480
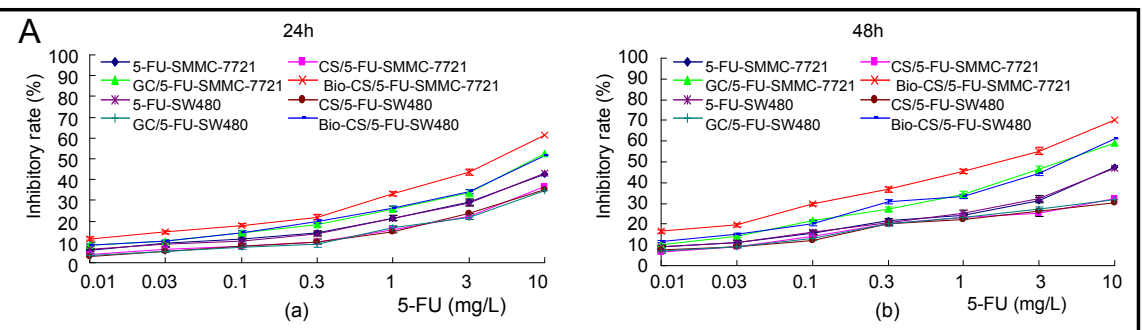

$72 \mathrm{~h}$

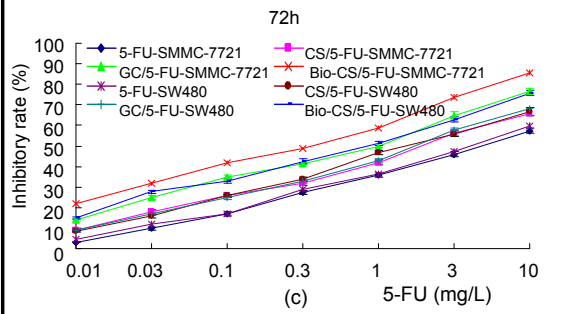

B

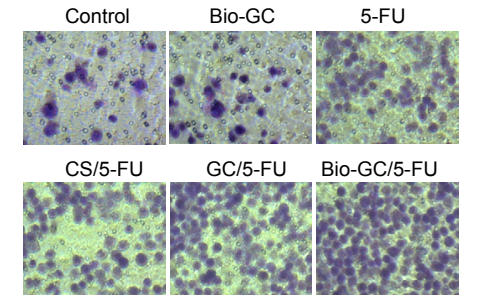

(a)

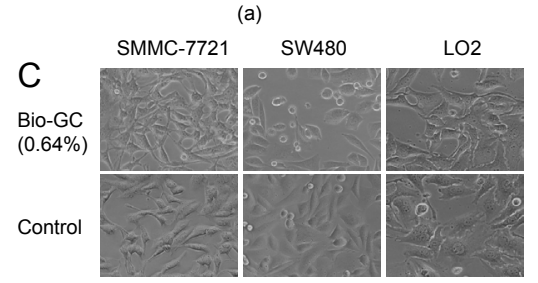

(a)
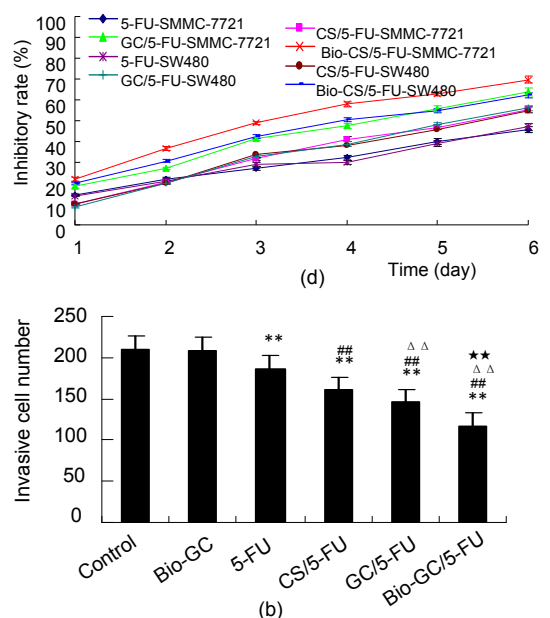

(b)

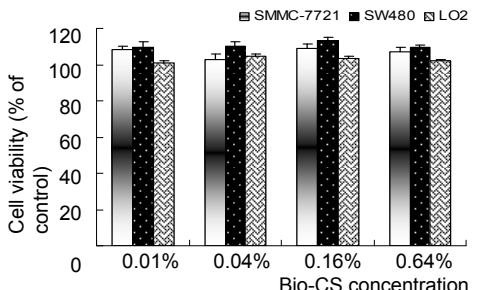

(b)

and SMMC-7721 at

$0.3 \mathrm{mg} / \mathrm{L}$ from days 1 to 6 . B: Migration of liver cancer cells after treatment of Bio-GC/5-FU nanoparticles. Liver cancer cells were incubated for $48 \mathrm{~h}$ in 5-FU, Bio-GC, CS/5-FU, GC/5-FU, or Bio-GC/5-FU and detected by transwell migration assay. (a): Microscope of upper chamber added with crystal violet $(\times 200)$. (b): Histogram of tumor cell numbers through the membrane observed by microscopy $(n=3)$. C: Cytotoxicity of Bio-GC nanomaterials. SMMC-7721, SW480, and LO2 cells were cultured with Bio-GC nanomaterial at concentrations from $0.01 \%$ to $0.64 \%$ for 3 days. Proliferation was evaluated by CCK-8. (a): Proliferation effects of Bio-GC nanoparticles at different concentrations. (b): Microscope images were screened after treatment with Bio-GC nanomaterials at concentrations of $0.64 \%(\times 200)$.

$(\mathrm{P}<0.01)$, and it was significantly higher in liver tissue in the presence of Bio-GC than when CS and Bio-CS $(\mathrm{P}<0.01)$ were present, but appeared significantly lower than that in the presence of GC $(\mathrm{P}<0.01)$.

The C/L ratio of Bio-GC was the highest (Fig. 3B (c)), which indicated that the Bio-GC containing ligands targeting both liver and liver cancer cells had the strongest liver cancer targeting properties. Bio-CS with mono-liver cancer targeting properties was weaker than Bio-GC. Although the fluorescence intensity of liver and liver cancer tissues with GC were significantly improved compared with $\mathrm{CS}$, the $\mathrm{C} / \mathrm{L}$ ratio was not significantly different between GC and CS, thus suggesting that GC has both liver and liver cancer targeting properties. Therefore, the liver cancer targeting properties of GC was not significantly better at targeting non-liver cancer tissue than CS. 


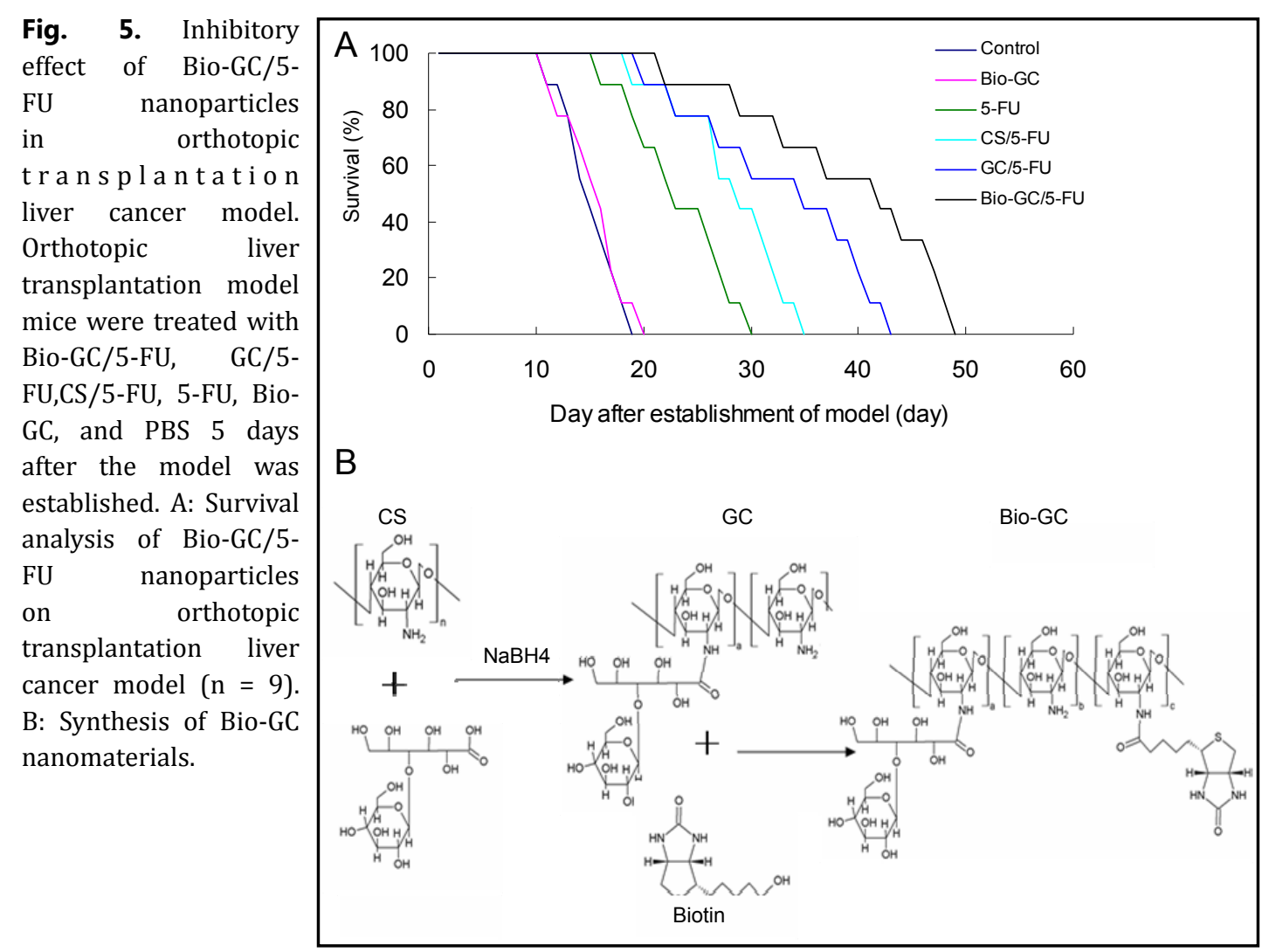

Liver target killing effect of Bio-GC/5-FU nanoparticles in liver cancer in a time- and dosedependent manner

As shown in Fig. 4A (a-c), as the concentration of Bio-GC/5-FU, GC/5-FU, GS/5-FU, and 5 -FU increased, the rate of inhibition increased significantly. The inhibitory effect was clearly enhanced from days 1 to 6 (Fig. 4A (d)). Bio-GC/5-FU has the strongest inhibitory effect on SMMC-7721 cells due to Bio-GC with both liver and liver cancer targeting properties, and the inhibition of SMMC-7721 cells mediated by GC/5-FU was no different from that of BioGC/5-FU in SW480 cells, which corresponded to GC nanoparticles with mono-liver cancer targeting properties for SMMC-7721 cells and Bio-GC nanoparticles with mono-cancer targeting properties for SW480 cells. The GS/5-FU nanoparticles had no targets on SMMC7721 and SW480 cells, hence the inhibition rates were no different between these cell lines. From days 1 to 2, the rates of GS/5-FU-mediated inhibition of SMMC-7721 and SW480 cells, and GC/5-FU-mediated inhibition of SW480 cells were lower than the 5-FU-mediated inhibition of SMMC-7721 and SW480 cells; however, from days 3 to 6 the inhibition rates were higher for GS/5-FU in SMMC-7721 and SW480 cells, and GC/5-FU in SW480 cells than for 5-FU in SMMC-7721 and SW480 cells. It was suggested that the concentration of 5-FU released from non-targeted nanomaterials was lower than that of 5-FU on days 1 to 2 , which resulted in a lower inhibitory rate. Moreover, from days 3 to 6 , the concentration of 5-FU released from non-targeted nanomaterials remained constant; thus, the rate of inhibition among non-targeted nanomaterials carrying 5-FU was significantly higher than that with 5-FU alone.

Effect of Bio-GC/5-FU nanoparticles on migration in liver cancer cells

As shown in Fig. 4B (a), the number of apoptotic cells in the upper chamber decreased in order of magnitude from Bio-GC/5-FU to GC/5-FU, to GS/5-FU, to 5-FU, to Bio-GC, to Control; thus, the Control and Bio-GC groups had the lowest number of apoptotic cells, while the highest number was in the Bio-GC/5-FU group. The numbers of liver cancer cells were also observed through the membrane in the lower chamber in Fig. 4B (b). The liver cancer cell counts increased in reverse order from Bio-GC/5-FU to GC/5-FU, to GS/5-FU, to 5-FU, with 


\section{Cellular Physiology Cell Physiol Biochem 2018;50:569-584 \begin{tabular}{ll|l} 
and Biochemistry $10.1159 / 000494169$ & $\begin{array}{l}\text { O } 2018 \text { The Author(s). Published by S. Karger AG, Basel } \\
\text { www.karger.com/cpb }\end{array}$
\end{tabular} \\ Cheng et al.: Inhibitory Effects of Bio-GC Nanoparticles Targeting Liver Cancer}

the lowest counts in Bio-GC/5-FU group and highest in Control and Bio-GC groups. This indicates that the nanomaterials can inhibit the migration of liver cancer cells and Bio-GC with its liver and liver cancer targeting properties had the strongest inhibitory effects on the migration of liver cancer cells. Moreover, the nanomaterials significantly enhanced the inhibitory effects of 5-FU on liver cancer.

\section{Toxic effects of Bio-GC nanoparticles on cells}

To assess the toxic effects of Bio-GC nanoparticles on cells, SMMC-7721, SW480, and LO2 cells were cultured with different concentrations of Bio-GC nanoparticles. After 72 $\mathrm{h}$, concentrations of $0.01-0.64 \%$ had no obvious inhibitory effects on the proliferation of SMMC-7721, SW480, and LO2 cells (Fig. 4B (b))-all groups showed proliferation rates of $100 \%$. As shown in Fig. 4C (a), when the cells were cultured with $0.64 \%$ nanomaterials, the proliferation rate was no different from that of the control group; thus, it was considered that even a high concentration of Bio-GC had no obvious cytotoxic effects on the cells. In this study, the concentration of the nanoscale materials in the drug delivery system was only $0.04 \%$, so it had no toxic side effects on cells.

Inhibition of Bio-GC/5-FU nanoparticles on orthotopic transplantation liver cancer model

After treatment, the mice in the control group started to die from day 11 (Fig. 5A), and all mice had died by day 19; the median survival time was 15 days. Mice in the Bio-GC group started to die at day 11 , and all mice had died by day 20; the median survival time was 16 days. Mice in 5-FU group started to die on day 16 and all mice had died by day 30; the median survival time was 23 days. Mice in the CS/5-FU group started to die on day 19 and all mice were dead by day 35; the median survival time was 29 days. Mice in GC/5-FU group started to die on day 20 , all mice had died by day 43 , and the median survival time was 35 days. Mice in Bio-GC/5-FU group started to die on day 22, all mice were dead on day 49 , and the median survival time was 42 days. These results showed that the Bio-GC/5-FU group had the longest survival times compared with the GC/5-FU and CS/5-FU groups $(\mathrm{P}<0.01)$, and the survival time in the GC/5-FU group was significantly longer than that in the CS/5-FU group $(\mathrm{P}<0.01)$.The efficacy of nanomaterials plus 5 -FU in the orthotopic transplantation liver cancer model was superior to single 5-FU; therefore, it is suggested that nanomaterials could help to heighten the suppressive effects on tumors, and Bio-GC with both liver cancer and liver targeting properties could improve the inhibitory effects of 5-FU in liver cancer more efficiently than GC with mono-liver targeting properties.

\section{Discussion}

5-FU has broad antitumor activities and has been widely used to treat digestive tract tumors. However, it is a non-selective antitumor drug similar to other anticancer drugs and because has a wide distribution and side effects in vivo, its clinical application is limited. To improve the efficacy of drugs, some scholars are exploring micro targeted, controlled release systems. Because of their good biocompatibility, serum proteins, hemoglobin, collagen, and gelatin as well as other natural biodegradable materials have been investigated widely; however their clinical application is limited because of the high costs, difficulties in the preparation of the materials and quality control, and the fact that they cannot be mass produced.

In recent years, attention has been paid to synthetic biodegradable polymers of nanomaterials, which not only have sustained and controlled release effects, but also have lesion site-targeting abilities, greater drug loading capacities, and other characteristics. They are expected to improve drug efficacy rates and reduce the number of side effects in normal tissues. In our previous study, we successfully synthesized GC with galactose and CS and found that the nanomaterial had liver and liver cancer targeting abilities. However, the higher drug concentration in liver tissue indicated that the nanomaterial had the shortcoming of not exclusively targeting liver cancer. It is evident that biotin has the ability to target cancer cells, such as in liver cancer [21], colon cancer [22], and breast cancer [23]. In particular, a study on hepatocellular carcinoma found that a large number of specific biotin receptors are present on human hepatocellular carcinoma cells, and nanomaterials combined with biotin have clear liver targeting effects; thus, biotin is a promising nanomaterial [24]. To overcome 
the aforementioned disadvantages, we grafted biotin onto GC nanomaterials to synthesize Bio-GC based on the knowledge that GC provides characteristic liver-directed transport (characteristics of semi lactose) and biotin targets the liver. Bio-GC nanomaterials have been successfully synthesized and confirmed by FT-IR spectra and ${ }^{1} \mathrm{H}-\mathrm{NMR}$.

Nano drug delivery systems refers to dispersion systems with particle sizes of 10-100 $\mathrm{nm}$. Their characteristics include excellent tumor targeting, long circulation times in vivo, easy absorption by cells, control of drug release and improved drug solubility, and increased drug stability. According to the tumor targeting characteristic, nano drug delivery systems are divided into active and passive groups. Passive targeting is achieved through the vascular wall by vascular endothelial cell gaps. Because of their high permeability and retention in solid tumors, nanoparticles can aggregate and be retained for a long time in tumor tissues [25]. The most appropriate particle size for passive targeting is $10-100 \mathrm{~nm}$, and endothelial cell gap allows particles up to $400 \mathrm{~nm}$ [26]. If the particles are larger than $100 \mathrm{~nm}$ or less than $10 \mathrm{~nm}$, they become trapped in the liver or are excreted by the kidney, respectively [27]. Active targeting is achieved mainly through grafting ligands onto the surface of the targeted delivery system, and the nano carrier system containing the target specific ligands is transported to the target recognition area and interacts with the cells where it delivers the medicine to the predetermined target. Due to the passive mode of the active drug delivery system entering the tumor tissue, most of these systems have no obvious advantages; hence, active targeting is used infrequently in clinical applications [28]. Therefore, the nanomaterial is particularly important for the control of passive targeting. In our study, galactose, which has liver tissue and liver cancer targeting properties, and biotin, which targets hepatocellular carcinoma, were grafted onto CS to form Bio-GC nanomaterials with liver cancer targeting properties (Fig. 5B). The particles were about $81.1 \mathrm{~nm}$ and the PI only 0.006 , so nanoparticle dispersion was good and in line with that of the ideal nanoparticle size.

To optimize the proportions of Bio-GC and 5-FU drugs, we found that a ratio in the range 1:1-1:8 was ideal. As 5-FU increased, Bio-GC drug loading increased gradually, and the encapsulation rate first increased then decreased as shown from the curve. When the Bio-GC/5-FU ratio was 1:4, the encapsulation rate was highest because the 5-FU loaded on the Bio-GC, reached saturation, and the encapsulation efficiency decreased when the ratio of Bio-GC/5-FU further increased. Therefore, the optimum ratio of Bio-GC/5-FU = 1:4 was used in our experiment. Scanning electron microscopy showed that the nanoparticles were spherical in shape and had smooth surfaces. The zeta potential was $+39.2 \mathrm{mV}$, and the drug loading capacity was $8.98 \%$. Our previous study found that $\mathrm{GC} / 5-\mathrm{FU}=1: 10$ is the best ratio [29], and when the Bio-GC nanomaterials were grafted with biotin, the proportions of 5-FU and the nanomaterials were significantly reduced, and the download quantity increased significantly at the same mass ratio, so the Bio-GC material has been optimized to a further extent than before. In the simulated fluid release, Bio-GC/5-FU showed 3 clear release phases: fast release, steady release, and slow release. In the fast release phase, release was rapid because of the fast diffusion of 5-FU physically encapsulated within the nanoparticles. In the steady release phase, the amide bonds of the nanomaterial were hydrolyzed and fractured, and 5-FU was steadily released. In the slow phase, the nanomaterial was slowly and completely degraded, which lead to the slow release of 5-FU. This approach is conducive to the orderly release of drugs and combination treatments of tumors, but it also needs to be verified in vivo experiments. The release of the nanomaterial can alter the distribution of drugs in the body, increasing the half-life, and reducing the risk of side effects [30].

Laser confocal microscopy also showed that Bio-GC nanoparticle mediated endocytosis was stronger than that of GC and non-targeted CS nanomaterials, and it was found that after treatment with Bio-GC in LO2 liver cells, only a small amount of green fluorescence was seen in the cells, which further confirmed that Bio-GC nanoparticles strongly target liver cancer cells because they actively target receptors. In pathological conditions (such as in tumors), the binding activity of galactose receptor declines [31], but cancer cells have a greater need for vitamins [32]; therefore, the activities of vitamin receptors in cancer cell also increase significantly. Biotin is also known as vitamin $\mathrm{H}$; its receptors are overexpressed in cancer cells and their activities also appear significantly enhanced [33]. Biotin grafted onto GC materials can significantly enhance the endocytosis of nanomaterials by cells., This was confirmed by the significantly greater expression of green fluorescence. Therefore, BioGC nanomaterials with galactose and biotin ligands have more targeted and stable effects in the treatment of liver cancer. 
To further verify the dynamic distribution of Bio-GC material in an orthotropic liver cancer mouse model, Bio-GC was marked by red fluorescent isothiocyanate with Luo Damming B. (Mouse spontaneous fluorescence is green, and to avoid and reduce interference, red fluorescent isothiocyanate with Luo Damming B was used.) To ensure that the fluorescence signal intensity was consistent among the nanomaterials, the nanomaterials and skeleton CS were labeled with isothiocyanic acid Luo Damming B. The nanomaterial skeleton CS was combined with rhodamine B isothiocyanate, then synthesized with the other nanomaterials. The study showed that the nanomaterial GC targeting the liver collected in the liver tissue and hepatocellular carcinoma tissues more than in other tissues in vivo. Therefore, it has obvious liver targeting but no hepatoma-specific targeting. Because the nanomaterial Bio-CS has only liver cancer targeting features, the concentration in liver tissue was lower than in liver cancer, and while Bio-CS has a strong liver cancer targeting effect, the total fluorescence signal was not high per unit area in liver cancer. However, Bio-GC has the advantage of both GC and Bio-CS nano properties, and the fluorescence signal appeared strongest in hepatocellular carcinoma and per unit area in liver cancer. Bio-GC, which showed the highest fluorescence intensity in liver cancer tissues may be related to the characteristics of the nanomaterials: Nanomaterials with two ligands targeting both the liver and liver cancer first enter the liver via the portal vein when injected into the tail vein, and accumulate in liver tissue because of the galactose ligand targets the liver [34]. Moreover, the nanomaterials gather at high concentrations in liver cancer tissues due to the liver cancer targeting characteristics of biotin, the second ligand [35]. Hepatoma cells can be targeted by the liver targeting ligand galactose and liver cancer targeting ligand biotin; therefore, the Bio-GC materials have dual liver cancer targeting effects in hepatoma cells, and at the same concentration, the affinity for tumor cells among more targeted nanomaterials is stronger than that of single targeted nanomaterials [36]. Hence, the concentrations of Bio-GC nanomaterials in hepatocellular carcinoma tissues were significantly higher than those of CS and Bio-CS nanomaterials.

Proliferation, invasion, and metastasis are important biological features of tumor cells, and significant causes of death in cancer patients $[37,38]$. In order to study the effect of BioGC/5-FU nanoparticles on the proliferation and invasion of hepatocellular carcinoma cells we conducted an experiment using Bio-GC/5-FU nanoparticles on hepatoma cells and found that Bio-GC/5-FU nanoparticles have time- and dose-dependent effects on hepatocellular carcinoma cells that clearly enhance the inhibition of cancer cells. We also found that the inhibitory effect of Bio-GC/5-FU nanoparticles on liver cancer cells was higher than on colon cancer cells, and Bio-GC/5-FU nanoparticles played a stronger inhibitory role in hepatocellular carcinoma cells than GC/5-FU nanoparticles. Consistent with the confocal microscopy results, Bio-GC/5-FU nanoparticles may have stronger endocytosis effects than GC/5-FU nanoparticles in hepatocellular carcinoma cells, which increase the intracellular concentration of 5-FU and enhance the inhibition of HCC growth. The tumor migration experiment showed that there were more apoptotic tumor cells above the transwell insert in the Bio-GC/5-FU group and significantly more than in GC/5-FU group, but there was a lower number of cells below the transwell insert in the Bio-GC/5-FU group compared with the GC/5-FU group. This indicated that Bio-GC/5-FU nanoparticles allowed the delivery of more 5-FU into hepatoma carcinoma cells via the biotin receptor and regulated the complex intracellular signal conduction by 5-FU to achieve significant inhibitory effects on the migration of liver cancer cells [39]. CS, galactose, and biotin have good biological compatibility and degradability, and have no obvious toxic side effects [40-42]. We synthesized Bio-GC nanomaterials and tested the toxicity of the Bio-GC nanomaterials. Tests showed that BioGC nanomaterials have no obvious side effects in normal liver cells, liver cancer cells, or colon cancer cells in the concentration range of $0.01-0.64 \%$. In this study, the concentration of experimental Bio-GC nanomaterials was only $0.04 \%$ and had the same clinical effects without any side effects.

To evaluate whether Bio-GC/5-FU nanoparticles also provided targeted inhibitory effects in an orthotopic transplantation liver cancer model, we injected Bio-GC/5-FU nanoparticles into the tail veins of mice after the model was established. Survival analysis showed that the Bio-GC/5-FU group survived significantly longer than the GC/5-FU, CS/5-FU, and 5-FU groups, indicating that CS/5-FU nanomaterial has a slow release effect compared with simple 5-FU treatment and that the curative effect of GC/5-FU nanoparticles on hepatocellular carcinoma was significantly higher than that of CS/5-FU nanoparticles, which further suggested that targeted therapy improved the efficacy of treatment in an orthotopic 


\section{Cellular Physiology Cell Physiol Biochem 2018;50:569-584 \begin{tabular}{ll|l} 
and Biochemistry & $\begin{array}{l}\text { DOI: 10.1159/000494169 } \\
\text { Publisned onlne: } 11 \text { October } 2018\end{array}$ & $\begin{array}{l}\text { O 2018 The Author(s). Published by S. Karger AG, Basel } \\
\text { www.karger.com/cpb }\end{array}$ \\
\cline { 2 - 3 }
\end{tabular} \\ Cheng et al.: Inhibitory Effects of Bio-GC Nanoparticles Targeting Liver Cancer}

transplantation liver cancer model. In this study, two ligands (galactose and biotin), were grafted to CS to synthesize a nanomaterial that targeted the receptors of galactose and biotin in liver cancer cells, enhanced the effect of targeted therapy, and significantly prolonged the survival of liver cancer model mice. The results indicated that Bio-GC nanomaterials provide more stable 5-FU endocytosis effects in hepatoma cells than single target nanomaterials, and due to the slow release of non-targeted nanomaterials, the concentration of 5-FU carried in the nanomaterials to hepatocellular carcinoma cells was more consistent than 5-FU alone; therefore, the curative effect via the inhibition of tumor cells was improved to some extent. The biggest obstacles in the clinical use of 5-FU are its toxicity and side effects, but our study found that Bio-GC nanoparticles reduced the toxic and side effects of 5-FU; therefore, they could play important roles in the delivery of chemotherapy drugs that are nontoxic or have few toxic effects.

\section{Conclusion}

Bio-GC nanomaterials were successfully synthesized and verified by FT-IR spectroscopy and ${ }^{1} \mathrm{H}-\mathrm{NMR}$. Bio-GC nanomaterials in vivo targeted liver cancer tissues, had an endocytosis effect on liver cancer, promoted the accumulation of 5-FU in liver cancer tissues, and promoted 5-FU-mediated targeted inhibition on liver cancer cells in a time- and dosedependent manner. In addition, Bio-GC showed significantly greater targeted inhibition of the proliferation and migration of liver cancer cells, and promoted the inhibitory effects of 5 -FU in an orthotopic transplantation liver cancer model.

\section{Abbreviations}

Bio-GC (biotin-modified galactosylated chitosan nanoparticles); FT-IR (Fourier transform infrared spectroscopy); ${ }^{1} \mathrm{H}-\mathrm{NMR}$ (hydrogen ${ }^{-1}$ nuclear magnetic resonance); $\mathrm{CS}$ (chitosan); 5-FU (5-Fluorouracil); ASGPR (Asialoglycoprotein receptor)

\section{Acknowledgements}

We thank Prof. Dejian Dai for the professional advice regarding this research.

This work was supported by the Public Health Bureau Youth Foundation of Shanghai (20134Y089). The funders had no input into the study, design, data collection, and analysis, decision to publish, and/or preparation of the manuscript.

All the data and materials supporting the conclusions are included in the main paper.

WPZ and MRC conceived and designed the experiments. MRC and KKZ performed the experimental work and analyzed the data. BCL and DXM participated in the experiments. All authors read and approved the final manuscript.

The study was approved by the ethics committee of the School of Life Sciences and Technology. All animal experiments were performed according to the National Institutes of Health guidelines on the use of experimental animals.

\section{Disclosure Statement}

The authors declare that they have no competing interests.

\section{References}

1 Aki F, Bando Y, Takahashi T, Uehara H, Numoto S, Ito S, Sasa M, Izumi K: A retrospective study on TS mRNA expression and prediction of the effects of adjuvant oral 5-fluorouracil in breast cancer. Oncol Lett 2010;1:981-987. 


\section{Cellular Physiology Cell Physiol Biochem 2018;50:569-584 and Biochemistry Published $\begin{aligned} & \text { DOI: 10.1159/000494169 } \\ & \text { C } 2018 \text { The Author(s). Published by S. Karger AG, Basel } \\ & \text { www.karger.com/cpb }\end{aligned}$

2 Li S, Zhu L, Yao L, Xia L, Pan L: Association between ERCC1 and TS mRNA levels and disease free survival in colorectal cancer patients receiving oxaliplatin and fluorouracil (5-FU) adjuvant chemotherapy. BMC Gastroenterol 2014;14:154.

-3 Sistonen J, Buchel B, Froehlich TK, Kummer D, Fontana S, Joerger M, van Kuilenburg AB, Largiader CR: Predicting 5-fluorouracil toxicity: DPD genotype and 5, 6-dihydrouracil:uracil ratio. Pharmacogenomics 2014;15:1653-1666.

4 Carlsson G, Odin E, Gustavsson B, Wettergren Y: Pretherapeutic uracil and dihydrouracil levels in saliva of colorectal cancer patients are associated with toxicity during adjuvant 5-fluorouracil-based chemotherapy. Cancer Chemother Pharmacol 2014;74:757-763.

5 Hu N, Yin JF, Ji Z, Hong Y, Wu P, Bian B, Song Z, Li R, Liu Q, Wu F: Strengthening gastric cancer therapy by Trastuzumab-Conjugated nanoparticles with simultaneous encapsulation of Anti-MiR-21 and 5-Fluorouridine. Cell Physiol Biochem 2017;44:2158-2173.

6 Wetzig T, Beckheinrich P, Rytter M, Haustein UF: Erosion of psoriatic plaques: An uncommon side-effect of neoadjuvant 5-fluorouracil treatment of colon cancer. Br J Dermatol 2002;147:824-825.

7 Sundqvist K, Hafstrom LO, Jonsson PE, Ryden S, Forsberg L, Lunderquist A: Treatment of liver cancer with regional intraarterial 5-FU infusion. Am J Surg 1978;136:328-331.

-8 Katona C, Kralovanszky J, Rosta A, Pandi E, Fonyad G, Toth K, Jeney A: Putative role of dihydropyrimidine dehydrogenase in the toxic side effect of 5-fluorouracil in colorectal cancer patients. Oncology-Basel 1998;55:468-474.

-9 He X, Yang L, Wang M, Zhuang X, Huang R, Zhu R, Wang S: Targeting the Endocannabinoid/CB1 receptor system for treating major depression through antidepressant activities of curcumin and DexanabinolLoaded solid lipid nanoparticles. Cell Physiol Biochem 2017;42:2281-2294.

10 Chen X, Sun J, Li H, Wang H, Lin Y, Hu Y, Zheng D: Curcumin-Loaded nanoparticles protect against Rhabdomyolysis-Induced acute kidney injury. Cell Physiol Biochem 2017;43:2143-2154.

-11 Manne N, Arvapalli R, Graffeo VA, Bandarupalli V, Shokuhfar T, Patel S, Rice KM, Ginjupalli GK, Blough ER: Prophylactic treatment with cerium oxide nanoparticles attenuate hepatic ischemia reperfusion injury in sprague dawley rats. Cell Physiol Biochem 2017;42:1837-1846.

12 Kang Y, Liu J, Song B, Feng X, Ou L, Wei L, Lai X, Shao L: Potential links between cytoskeletal disturbances and electroneurophysiological dysfunctions induced in the central nervous system by inorganic nanoparticles. Cell Physiol Biochem 2016;40:1487-1505.

13 Wang C, Blough E, Dai X, Olajide O, Driscoll H, Leidy JW, July M, Triest WE, Wu M: Protective effects of cerium oxide nanoparticles on MC3T3-E1 osteoblastic cells exposed to X-Ray irradiation. Cell Physiol Biochem 2016;38:1510-1519.

14 Mitra A, Dey B: Chitosan microspheres in novel drug delivery systems. Indian J Pharm Sci 2011;73:355366.

15 Ribeiro TG, Franca JR, Fuscaldi LL, Santos ML, Duarte MC, Lage PS, Martins VT, Costa LE, Fernandes SO, Cardoso VN, Castilho RO, Soto M, Tavares CA, Faraco AA, Coelho EA, Chavez-Fumagalli MA: An optimized nanoparticle delivery system based on chitosan and chondroitin sulfate molecules reduces the toxicity of amphotericin B and is effective in treating tegumentary leishmaniasis. Int J Nanomedicine 2014;9:53415353.

16 Cheng M, Han J, Li Q, He B, Zha B, Wu J, Zhou R, Ye T, Wang W, Xu H, Hou Y: Synthesis of galactosylated chitosan/5-fluorouracil nanoparticles and its characteristics, in vitro and in vivo release studies. J Biomed Mater Res B Appl Biomater 2012;100:2035-2043.

17 Fallon RJ, Danaher M, Saxena A: The asialoglycoprotein receptor is associated with a tyrosine kinase in HepG2 cells. J Biol Chem 1994;269:26626-26629.

18 Cheng M, He B, Wan T, Zhu W, Han J, Zha B, Chen H, Yang F, Li Q Wang W, Xu H, Ye T: 5-Fluorouracil nanoparticles inhibit hepatocellular carcinoma via activation of the p53 pathway in the orthotopic transplant mouse model. Plos One 2012;7:e47115.

19 Yang W, Cheng Y, Xu T, Wang X, Wen LP: Targeting cancer cells with biotin-dendrimer conjugates. Eur J Med Chem 2009;44:862-868.

20 Heo DN, Yang DH, Moon HJ, Lee JB, Bae MS, Lee SC, Lee WJ, Sun IC, Kwon IK: Gold nanoparticles surfacefunctionalized with paclitaxel drug and biotin receptor as theranostic agents for cancer therapy. Biomaterials 2012;33:856-866.

21 Qu W, Chen WH, Kuang Y, Zeng X, Cheng SX, Zhou X, Zhuo RX, Zhang XZ: Avidin-biotin interaction mediated peptide assemblies as efficient gene delivery vectors for cancer therapy. Mol Pharm 2013;10:261-269.

-22 Babak MV, Plazuk D, Meier SM, Arabshahi HJ, Reynisson J, Rychlik B, Blauz A, Szulc K, Hanif M, Strobl S, Roller A, Keppler BK, Hartinger CG: Half-Sandwich Ruthenium(II) biotin conjugates as biological vectors to cancer cells. Chemistry 2015;21:5110-5117. 


\section{Cellular Physiology Cell Physiol Biochem 2018;50:569-584

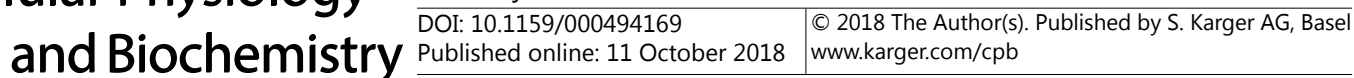 \\ Cheng et al.: Inhibitory Effects of Bio-GC Nanoparticles Targeting Liver Cancer}

-23 Vadlapudi AD, Vadlapatla RK, Pal D, Mitra AK: Biotin uptake by T47D breast cancer cells: Functional and molecular evidence of sodium-dependent multivitamin transporter (SMVT). Int J Pharm 2013;441:535543.

24 Aswathy J, Jahnavi S, Krishna R, Manzoor K, Nair S, Menon D: Targeted labeling of cancer cells using biotin tagged avidin functionalized biocompatible fluorescent nanocrystals. J Nanosci Nanotechnol 2011;11:7611-7620.

-25 Haley B, Frenkel E: Nanoparticles for drug delivery in cancer treatment. Urol Oncol 2008;26:57-64.

26 Maruyama K: Intracellular targeting delivery of liposomal drugs to solid tumors based on EPR effects. Adv Drug Deliv Rev 2011;63:161-169.

27 Lammers T: Drug targeting to tumors: Principles, pitfalls and (pre-) clinical progress. 2012;161:175-187.

28 Xu Q, Liu Y, Su S, Li W, Chen C, Wu Y: Anti-tumor activity of paclitaxel through dual-targeting carrier of cyclic RGD and transferrin conjugated hyperbranched copolymer nanoparticles. Biomaterials 2012;33:16271639.

29 Cheng M, Han J, Li Q, He B, Zha B, Wu J, Zhou R, Ye T, Wang W, Xu H, Hou Y: Synthesis of galactosylated chitosan/5-fluorouracil nanoparticles and its characteristics, in vitro and in vivo release studies. J Biomed Mater Res B Appl Biomater 2012;100:2035-2043.

30 Kim JH, Kim YS, Park K, Lee S, Nam HY, Min KH, Jo HG, Park JH, Choi K, Jeong SY, Park RW, Kim IS, Kim K, Kwon IC: Antitumor efficacy of cisplatin-loaded glycol chitosan nanoparticles in tumor-bearing mice. J Control Release 2008;127:41-49.

-31 Tian Q, Zhang CN, Wang XH, Wang W, Huang W, Cha RT, Wang CH, Yuan Z, Liu M, Wan HY, Tang H: Glycyrrhetinic acid-modified chitosan/poly(ethylene glycol) nanoparticles for liver-targeted delivery. Biomaterials 2010;31:4748-4756.

-32 Lu Y, Low PS: Folate-mediated delivery of macromolecular anticancer therapeutic agents. Adv Drug Deliv Rev 2002;54:675-693.

-33 Sakahara H, Saga T: Avidin-biotin system for delivery of diagnostic agents. Adv Drug Deliv Rev 1999;37:89101.

-34 Wei W, Yue ZG, Qu JB, Yue H, Su ZG, Ma GH: Galactosylated nanocrystallites of insoluble anticancer drug for liver-targeting therapy: An in vitro evaluation. Nanomedicine (Lond) 2010;5:589-596.

35 Hu Y, Li K, Wang L, Yin S, Zhang Z, Zhang Y: Pegylated immuno-lipopolyplexes: A novel non-viral gene delivery system for liver cancer therapy. J Control Release 2010;144:75-81.

-36 Jing F, Li J, Liu D, Wang C, Sui Z: Dual ligands modified double targeted nano-system for liver targeted gene delivery. Pharm Biol 2013;51:643-649.

37 Liu YF, Yang A, Liu W, Wang C, Wang M, Zhang L, Wang D, Dong JF, Li M: NME2 reduces proliferation, migration and invasion of gastric cancer cells to limit metastasis. Plos One 2015;10:e115968.

-38 Li J, Jia L, Ma ZH, Ma QH, Yang XH, Zhao YF: Axl glycosylation mediates tumor cell proliferation, invasion and lymphatic metastasis in murine hepatocellular carcinoma. World J Gastroenterol 2012;18:5369-5376.

-39 Gordon SR, Climie M, Hitt AL: 5-Fluorouracil interferes with actin organization, stress fiber formation and cell migration in corneal endothelial cells during wound repair along the natural basement membrane. Cell Motil Cytoskeleton 2005;62:244-258.

40 Muzzarelli C, Muzzarelli RA: Natural and artificial chitosan-inorganic composites. J Inorg Biochem 2002;92:89-94.

41 Chen H, Li M, Wan T, Zheng Q Cheng M, Huang S, Wang Y: Design and synthesis of dual-ligand modified chitosan as a liver targeting vector. J Mater Sci Mater Med 2012;23:431-441.

$>42$ Boado RJ, Pardridge WM: Complete protection of antisense oligonucleotides against serum nuclease degradation by an avidin-biotin system. Bioconjug Chem 1992;3:519-523. 